\title{
Feasibility of injectable Depot medroxyprogesterone acetate in a semi urban camp setting
}

\author{
Ruchira Nautiyal $^{1}$, Rajeev Bijalwan ${ }^{2}$, B. Maithili ${ }^{2}$, Latika N. Sinha ${ }^{2}$
}

\begin{abstract}
${ }^{1}$ Department of Obstetrics and Gynecology, Himalayan Institute of Medical Sciences, SRH University, Dehradun, Uttarakhand, India

${ }^{2}$ Rural Development Institute, Himalayan Institute of Medical Sciences, Dehradun, Uttarakhand, India
\end{abstract}

Received: 15 February 2016

Accepted: 11 March 2016

\section{*Correspondence:}

Dr. Ruchira Nautiyal,

E-mail: drnauty1@rediffmail.com

Copyright: () the author(s), publisher and licensee Medip Academy. This is an open-access article distributed under the terms of the Creative Commons Attribution Non-Commercial License, which permits unrestricted non-commercial use, distribution, and reproduction in any medium, provided the original work is properly cited.

\section{ABSTRACT}

Background: The contraceptive method mix in India has been dominated by female sterilization for a long time. Initiatives have been taken to make Depot medroxyprogesterone acetate (DMPA) available through the public sector of the country. Considering the privacy, safety and efficacy of this long acting method, the study was undertaken to evaluate the acceptance of DMPA in field camps amongst semi urban population.

Methods: A cross sectional evaluation study was carried out with married women who accepted DMPA from the basket of contraceptives offered to them. Selection was facilitated by adequate counseling. After counseling, the clients were followed up during subsequent doses for a year for the acceptance and side effects. A checklist was filled comprising detailed history and other variables. The data was expressed in number and percentage and statistical analysis was done on SPSS - 19.

Results: The mean age of 45 eligible women who accepted DMPA was 26.5 years .Fifty one percent of women were primiparous and forty two percent were lactating during the study period. Majority (80\%) were self-motivated to receive subsequent injections. There was no pregnancy in DMPA users. The commonest adverse effect was amenorrhea (49\%) followed by irregular spotting (32\%) and menorrhagia (14\%). Fourteen subjects discontinued DMPA after one or two injections but $58.5 \%$ acceptors considered this a good method for birth spacing and wanted to continue it for a longer period.

Conclusions: DMPA remains a valid, safe and confidential but neglected contraceptive in India. There is a need to create an awareness program for common people and also to build a supportive environment for users at all levels.

Keywords: DMPA, Contraceptives, Injectable contraceptive, Progesterone contraceptives

\section{INTRODUCTION}

The total contraceptive prevalence rate ( CPR) in India among married woman is estimated at $56.3 \%$ as per NFHS-3 data. ${ }^{1}$ This is comparatively lower than neighbouring countries like Bhutan, Bangladesh and Sri Lanka whose CPR stands at $65.6 \%, 61.2 \%$ and $68.4 \%$ respectively. ${ }^{2}$ In India primary method of family planning is female sterilization at $65.7 \%$ which is the highest in the world . One of the key reasons is limited availability of wide range of contraceptive methods in public health sector of the country .India gives only four options in basket of contraceptive methods in the public sectorcondom, sterilization, pills and intrauterine device. ${ }^{3}$ Injectables are there in the private sector for over two decades for commercial use but their usage has been limited. Indeed, only $0.1 \%$ of married women were using injectable in 2005-2006. They are not included in Government of India family planning program because of fears expressed by many authorities about their appropriateness and quality of services. ${ }^{5}$ The rapid use of long acting injectable contraceptives in African countries and with $49 \%$ and $21 \%$ users of injectable in Indonesia and Bangladesh respectively rekindles the faith of the 
health care providers in them. ${ }^{4,6,7}$ We therefore wanted to study the acceptance of injectable contraceptive Depot Medroxyprogesterone Acetate (DMPA) in the field camps setting in semi urban population. The impact of quality counselling on patient motivation for continued use of DMPA was also determined as a secondary objective.

\section{METHODS}

This was a cross sectional evaluation study carried out on women of reproductive age of Rajeev Nagar, Doiwala who were seeking contraceptive in a weekly camp setting organized by Rural Development Institute of Himalayan Institute of Medical Sciences, Dehradun, India .The study duration was twelve months. The clients opting for injectable contraceptive, which was made available for the camp at a subsidized rate of hundred rupees (1.50 US dollar), were recruited in the study. In this family planning camp other methods of contraception were also offered to the clients and those willing for any of them other than injectable DMPA were accordingly provided. Clients opting for injectable contraceptives were screened based on the checklist by the consultant gynaecologist (available at the camp) for the contraindications, then Injection Depot medroxyprogesterone acetate (DMPA) was given in the dose of $150 \mathrm{mg}$ deep intramuscular in the gluteal region every 3 monthly for four doses.A trained counsellor filled the necessary proforma which included the subject's socio demographic details, obstetric history, menstrual history, weight, blood pressure and questions related to their contraceptives status and compliance. She counselled the clients about the method, three monthly follow up, benefits and the adverse effects at every visit. The subjects were thus followed up for one year at this centre. Socio demographic variables, demand and acceptance, various adverse effects were studied using SPSS software version 17. Dropout rate and reasons for them were studied simultaneously. In conclusion, appropriateness to include injectable in the basket of contraceptive choices in community level family planning services was assessed during this period.

\section{RESULTS}

The estimated numbers of eligible couples in the study area were 3500 . There were 45 eligible women who opted for injectable DMPA in our study. They were monitored for one year for their compliance. Majority of the women who adopted this method were between the ages of 21-30 years. Mean age was 26.5 years (19-34). 19 subjects were lactating and wanted to continue with it. Though acceptance of this method was better with women who were educated beyond high school (52\%) yet lesser educated ones were equally open to receive DMPA as a contraceptive. We didn't have grand multipara in our study because most of them in our study area had undergone sterilization or refrained from using any contraceptive as per their religious and cultural beliefs. According to Table 2 most of the patients were self- motivated to come for repeat injections and only a few needed a reminder from their spouse or ASHA through SMS. Various side effects of DMPA used are listed in Table no 3 due to which 14 patients opted out of the study after initial doses (Table 4).

Table 1: Patient's characteristics $(\mathrm{N}=\mathbf{4 5})$.

\begin{tabular}{|lll|}
\hline Age group (years) & No. & Percentage \\
\hline$<20$ & 6 & 14 \\
\hline $21-30$ & 37 & 82 \\
\hline$>30$ & 2 & 4 \\
\hline Mean age & & \\
\hline Education status & & 48 \\
\hline Primary & 22 & 52 \\
\hline$\geq$ High school & 23 & \\
\hline Parity & & 51 \\
\hline Primipara & 24 & 49 \\
\hline Multi & 21 & \\
\hline Prior contraceptives & & 24 \\
\hline OCPs & 11 & 12 \\
\hline Barrier & 5 & 20 \\
\hline Natural methods & 9 & 44 \\
\hline None & 20 & \\
\hline
\end{tabular}

Table 2: Motivators for DMPA doses $(\mathrm{N}=45)$.

\begin{tabular}{|lll|}
\hline Motivators/Reminders & No & Percentage \\
\hline ASHA/counsellors & 1 & 3 \\
\hline Husband & 8 & 17 \\
\hline Self & 36 & 80 \\
\hline
\end{tabular}

Chi square $=0.08 ; \quad \mathrm{P}=0.635$

Table 3: Reported side effects $(\mathrm{N}=45)$.

\begin{tabular}{|lll|}
\hline Side effects & No. & Percentage \\
\hline Amenorrhoea & 22 & 49 \\
\hline Irregular spotting per vaginum & 15 & 32 \\
\hline Heavy bleeding per vaginum & 6 & 14 \\
\hline Anxiety & 2 & 5 \\
\hline
\end{tabular}

Table 4: Discontinuation of DMPA doses $(\mathrm{N}=45)$.

\begin{tabular}{|lll|}
\hline Dropout rate b/w injections & No & Percentage \\
\hline After 1 injection & 2 & 6 \\
\hline After 2 injections & 12 & 26 \\
\hline
\end{tabular}

Chi square $=0.13 ; \mathrm{P}=0.536$

\section{DISCUSSION}

Depot medroxyprogesterone acetate (DMPA) is a long acting injectable contraceptive that works by inhibiting pituitary gonadotropins resulting in anovulation. It exists as an effective, safe and convenient method for birth spacing since 1994 in the private sector of the country. The contraceptive prevalence of injectable is $3.5 \%$ worldwide. $^{8}$ It is $15 \%$ for Sri Lanka, $10 \%$ for Nepal, $7 \%$ 
for Bangladesh, $5.9 \%$ for Bhutan and $2.7 \%$ for Pakistan whereas nationally the current use of DMPA is $0.1 \% .^{4}$ It has a very low failure rate compared to condoms and implants if used as recommended. The failure rate is $0.3 \%$, if correctly and consistently use and $3 \%$ in typical use. $^{9,10}$ In this small study of 45 eligible women who accepted DMPA injectable, no pregnancies occurred ,thus the Pearl index was zero. Similar results were obtained in Karnataka study, Chinese study and also a low rate of pregnancy $(0.08 \%)$ was reported by Aktun et al. ${ }^{11-13}$

The mean age of women in our study was 26.5 years which was comparable to Rai and Khan et al (27years). $51 \%$ clients who had one child opted for this method for birth spacing whereas $21 \%$ primipara chose DMPA compared to multipara in Rai study and similar results were also observed by Khan et al. ${ }^{11,14}$ It is because in India women are less aware and less informed about spacing methods. Instead, they are motivated to undergo sterilization once they achieve their desired family size. It was seen that those who feared or were disallowed tubal ligation went for DMPA. This trend was noticeably seen in Muslims, though no quantitative assessment was done for the same. Nearly $50 \%$ of the subjects were high school pass but it was surprising that only one third of the study population was using substantial method of birth spacing. On inquiry, it was found that they either relied upon lactation amenorrhoea method or nothing. During counselling, the acceptors came up with various myths and misconceptions which were cleared by the counsellor. The commonest misconception in the community was that protection is for five years which was clarified during the counselling.

19 acceptors (42\%) were lactating when opted for DMPA and did not report any adverse effect on the milk quantity and quality while they continued with their doses .DMPA can be safely offered to postpartum and lactating women who find it attractive over Intrauterine Device. ${ }^{12,13}$ Singhalet al studied the impact of short term use of DMPA on breast feeding performance and reported nearly hundred percent satisfaction in primipara regarding lactation amount. ${ }^{15}$ Higher continuation rates of $60 \%$ and more in the postpartum women were also quoted by others. ${ }^{11,16}$ Therefore, DMPA is a feasible option during lactation when estrogen containing contraceptives are not favoured.

Compliance with DMPA is an issue mainly because of its menstrual side effects. ${ }^{17}$ Amenorrhoea was the main side effect in our study followed by spotting per vaginum. Irregular bleeding and disruption of menstrual cycle has also been observed by Aktun et al and Rai et al in $65 \%$ $80 \%$ of women in their studies.${ }^{11,13}$ Women can be counselled that amenorrhoea and reduction in menstrual cramps if develops as a side effect, can be viewed as an advantage. ${ }^{18}$ Menorrhagia which was common with first and second dose of injectable was reported by six clients in our study .It was managed with tablet of tranexaemic acid $(500 \mathrm{mg})$ along with iron tablets but three of them dropped out after two injections despite counselling, citing spousal disagreement. $58.5 \%$ acceptors of injectable considered it as a good method for birth spacing in our study and wanted to continue it for a longer period. The reasons quoted for preferring DMPA over other methods were its convenience, confidentiality with the method and simply because it suited them. Some visited the camp for other ailments but were interested in contraceptive counselling regarding DMPA and received the first injection. Pilot studies in Uttar Pradesh and Rajasthan also showed that $80 \%$ women believed DMPA is a good method. ${ }^{14} \mathrm{~A}$ strikingly higher inclination of women towards injection DMPA was seen in African countries. This was more in rural than in urban areas and women gave secrecy, privacy and cultural preference as the main reason. They considered injection as 'vaccination' against unwanted pregnancies. ${ }^{19}$

Discontinuation rate in our study is only $32 \%$ whereas it ranges from $42.5 \%$ to as high as $71 \% .^{11,13,14}$ Internationally, these rates range from $44 \%$ to $56 \%$ at 12 months. $^{20}$ Discontinuation mainly due to menstrual disturbances ranges from $15 \%-50 \%{ }^{21}$ and this was the main reason for dropping out after one or two injection in our study. Though these effects are self-limiting or can be managed by a combination of structured intensive counselling and multiple contacts and reminders yet for the semi urban and rural women this remains the limiting factor. Many women wanted to remain hassle free and preferred their natural contraceptive practices despite counselling, whereas others looked up to their peer's experiences and were convinced to continue with the injections. It is established that pre-treatment counselling on expected side effects and their management improves acceptability of DMPA. ${ }^{18,22,23}$ It was seen, women who were told to come for side effects and those who received information, continued more with injectable contraceptives. $^{12,24,25}$

Apart from the side effects, other pertinent reason for discontinuation was the cost of the injection and its nonavailability at the public sector. ${ }^{17}$ In 1996 Parivar Seva Sanstha (PSS) conducted study in three cities of Uttar Pradesh and found that the acceptance of DMPA was lowest in the city where prices were highest. As a part of the study, we dispensed DMPA at a subsidized rate of hundred rupees, but realized that for clients even nominal cost is a burden. This opinion was put forward after the pilot project in Uttar Pradesh and Rajasthan and researchers proposed that the maximum cost of DMPA for rural areas could be 40 rupees, as once the price was more than 60 rupees it lead to a drastic decline in acceptance. ${ }^{26}$ We hope that financial issues would be addressed soon as there is a recent nod by Ministry of Health and Family Welfare and Drug Testing Advisory Board (DTAB) to introduce injectables in the basket of contraceptive choices. There are several women groups and studies concerned with women's health opposing injectables contraceptives especially regarding Osteoporosis and Breast cancer. Studies in South Africa 
show no direct link between DMPA and breast cancer. Long term users of DMPA were found to have no adverse effect on breast cancer whereas in recent users it may trigger the growth of existing breast tumours. ${ }^{27}$ Gold and Bachrach and others highlighted a major adverse effect on Bone Mineral Density (BMD) in adolescents. ${ }^{28,29}$ To address this issue and following other studies on longer term safety of DMPA, both WHO and American College of Obstetricians and Gynecologists (ACOG) recommended against any restrictions on the use of DMPA. ${ }^{30-33}$ W.H.O convened a consultative meeting in Geneva (2007) and concluded that the reduction in BMD may occur in females who have attained peak bone mass but when the use is discontinued ,BMD returns to normal over 2-3 years. It recommends that there is no restriction on the use of injectable contraceptives between 18-45 years old who are otherwise eligible the potential impact on BMD must be balanced against the individual. There is no need of routine BMD monitoring nor supplementation of vitamin $\mathrm{D}$ or calcium with DMPA. $^{34,35}$ As there is no ideal contraceptive which can appeal to all ages, health care providers need to offer various options to the client who has a right to exercise her choice .Improper selection of clients and inappropriate timing of reinjections may reflect as low effectiveness of injectable contraceptives therefore this should be taken into consideration. ${ }^{36}$ Once DMPA is chosen by the clients, during follow up visits the woman can be approached holistically and can be screened for other pathologies too. It is seen 3\%-53\% married women have knowledge about DMPA but their access to it is limited. 69\% users obtain their DMPA from a private hospital or private doctor. ${ }^{4}$ So, demand and supply issues need to be addressed when DMPA comes into the basket of contraceptives. Acceptance is highest when the injections are free but free services cannot sustain continued acceptance so it is imperative that the issue is resolved judiciously. Ours is a preliminary study with its weakness. The limitation of our study is that it is a small study with a limited sample size and a non-randomized one and therefore statistical analysis is limited. But its strength lies in the fact that as it was a scheduled weekly camp where clients were recruited after screening by the specialist and later attended by a dedicated counsellor, counselling was uniform and follow up was without bias.

\section{CONCLUSION}

DMPA is a safe, effective, reversible but neglected long acting injectable. Indian women shall now have the right to choose a globally popular contraceptive once this becomes freely accessible through public sector. But there is a need to develop standardized protocols for counselling, training of ASHA and ANMs and strengthening of health system. However, in Uttarakhand, more publicity and awareness about this method is needed.

Funding: Not required

Conflict of interest: None declared
Ethical approval: The study was approved by the Institutional Ethics Committee

\section{REFERENCES}

1. Taneja DK, Banerjee B. Demographic and health Information of India. $12^{\text {th }}$ ed.New Delhi:Doctors Publications. 2014; Health Policies and programmes in India; pp.38-40.

2. Ministry of Health and Family Welfare (MOHFW) and United Nations Population Fund, India. Contraceptive updates: Reference manual for doctors. 2005; New Delhi: MOHFW, Government of India

3. Family Health International (FHI). Types, availability, and use of injectables. FHI Briefs2010; India Brief 3. New Delhi: Family Health International.

4. International Institute for Population Sciences (IIPS) and Macro International. 2007. National Family Health Survey (NFHS-3), 2005-06: India: Volume 1. Mumbai: IIPS.

5. Sarojini NB, Murthy L. Why women's groups oppose injectable contraceptives. Indian $\mathrm{J}$ Med Ethics. 2005;2(1):8-9.

6. Otayli N. Progestogen - Only Injectable contraceptives and bone health, IPPF Medical Bulletin. 2006;40(2):5-6

7. Lande R, Richey C. Expanding services for injectables. Population Reports.2006; Series K, No. 6. Baltimore: Info project, John Hopkins Bloomberg School of Public Health.

8. Department of Economic and Social Affairs,PopulationDivision2011. World contraceptive use2011.NewYork:United Nations.Available at:http://www.un.org/esa/population/publication/cont raceptive2011/Contraceptive2011.htm.

9. World Health Organisation (WHO). Medical eligibility criteria for contraceptive use: A WHO family planning cornerstone. 2010;Geneva: WHO.

10. Trussell J. The essentials of contraception: efficacy, safety, and personal considerations. In: Hatcher RA, Trussell J, Stewart F, Nelson A, Cates W, Guest F, Kowal D editor. Contraceptive technology: eighteenth revised edition. New York, NY: Ardent Media. 2004:221-52.

11. Rai L, Prabakar P. Injectable depot medroxyprogesterone - a safe and an effective contraception for an Indian setting," Health and Population Perspectives and Issues. 2007;30(1):1223.

12. Danli S, Qingxiang S, Guowei S. A multicentered clinical trial of the long-acting injectable contraceptive Depo Provera in Chinese women.Contraception. 2000;62(1):15-8.

13. Aktun H, Moroy P, Cakmak P, Yalcin HR, Leyla M. Use of a Long-acting Progestin Injectable Contraceptive in Turkish Women, Contraception. 2005;72(1):24-7. 
14. Khan ME, Dixit A, Ahmad J. Introduction of DMPA in public health facilities of Uttar Pradesh and Rajasthan. An evaluation .Project brief .New Delhi, India: Population council, 2015.

15. Singhal S, Sarda N, Gupta S. Impact of injectable Progestogen Contraception in early puerperium on Lactation and Infant health. J Clin Diagn Res. 2014;8(3):69-72.

16. Krishna U, Mandlekar A and Raote V .Long-Acting Injectables - Acceptability and Efficacy in our Family Welfare Programmeme, J ObstetGynecol India. 1999;49(6):40-6.

17. United Nations Population Fund, India. Expandingcontraceptive options: experiences of users and providers with progestin only injectable contraceptive -DMPA. Findings of a multi-centric study. New Delhi, India: UNFPA; 2004.

18. Nelson AL. Counseling issues and management of side effects for women using depot medroxyprogesterone acetate contraception. J Reprod Med. 1996;41(5 suppl ):391-400.

19. Adetunji J. Rising popularity of injectable contraceptives in sub-Saharan Africa, African Population Studies. 2011;25(2):587-604.

20. Vaughan B, Trussell J. Discontinuation and resumption of contraceptive use: Results from the 2002 National Survey of Family Growth, Contraception. 2008;78(4):271-83.

21. Hirve $S$ Injectables as a Choice-Evidence-based Lesson. Indian J Medical Ethics. 2005;11(1):12-3.

22. Wu SC, Garceau RJ, Jiangs, Yang QZ, Wang WZ. Effect of pretreatment counseling on discontinuation rates in chinese women given Depot Medroxypregesterone acetate for contraception. Contraception. 1996;53(6):357-61.

23. Strategies to improve adherence and acceptability of hormonal methods of contraception .Cochrane database syst Rev. 2013;10:CD004317.

24. Hubacher D, Goco N, Gonzalez B, Taylor D. Factors effecting continuation rates of DMPA. Contraception. 1999;60;(6):345-51.

25. Canto De Cetina, Canto P, Ordonezluna M. Effect of Counseling to Improve Compliance in Mexican Women receiving Depot Medroxyprogesterone Acetate, Contraception. 2001;63(3):143-6.

26. Tiwari S, Vishwanath S, Singh H. DMPA provision in PSS clinics in Uttar Pradesh: cost and prices. Technical paper 10. New Delhi, India, Population council and Parivar Seva Sanstha; 1997.
27. Shapiro S, Rosenberg L, Hoffman M, Truter H. Risk of Breast Cancer in Relation to the Use of Injectable Progestogen Contraceptives and Combined Estrogen/Progestogen Contraceptives, Am J Epidemiol. 2000;151:396-403.

28. Gold MA, Bachrach LK. Contraceptive use in teens: a threat to bone health? Journal of Adolescent Health. 2004;35:427-9.

29. Johnson CC, Burkman RT, Gold MA, Brown RT, Harel Z, Bruner A, et al. Longitudinal study of depot medroxyprogesterone acetate (Depo-Provera) effects on bone health in adolescents: study design, population characteristics and baseline bone mineral density. Contraception. 2008;77(4):239-42.

30. Kaunitz AM, Arias R, McClung M. Bone density recovery after depotmedroxyprogesterone acetate injectable use.Contraception. 2008:67-77.

31. Guilbert ER, Brown JP, Kaunitz AM, Wagner MS. The use of depot medroxyacetate in contraception and its potential impact on skeletal health. Contraception. 2009;79(3):166-77.

32. Gbolade B, Ellis S, Murby B, Randall S and Kirkman R .Bone Density in Long-term Users of Depot Medroxyprogesterone Acetate, Br J Obstet Gynecol. 1998;105:790-4.

33. Trussell J. Choosing a contraceptive: efficacy, safety, and personal considerations. In: Hatcher RA, Trussell J, Nelson AL, Cates W, Stewart FH, Kowal D editor. Contraceptive technology: nineteenth revised edition. New York, NY: Ardent Media. 2007:19-47.

34. WHO. Technical consultation on the effects of hormonal contraception on bone health.Geneva:WHO;2007.Availaible at: http://whqlibdoc.who.int/hq/2007/WHO_RHR_07.08 _eng.pdf?ua=1.

35. American College of Obstetricians and Gynecologists Committee on Gynecologic Practice. ACOG Committee Opinion No.415:depot medroxyprogesterone acetate and bone effects. Obstet Gynecol. 2008;112(3):727-30

36. Phadke A. A Thorough Critique of Depo-provera Book Review. Indian J Medical Ethics. 2005;11(1):30.

Cite this article as: Nautiyal R, Bijalwan R, Maithili B, Sinha LN. Feasibility of injectable Depot medroxyprogesterone acetate in a semi urban camp setting. Int J Reprod Contracept Obstet Gynecol 2016;5:1056-60. 